\title{
Understanding unintended pregnancy in Senegal: Country profile report
}

Kaila Clarke

Mohamadou Sall

Babacar Mane

Population Council

Nafissatou Diop

Population Council

Bocar Mamadou Daff

Follow this and additional works at: https://knowledgecommons.popcouncil.org/departments_sbsr-rh

Part of the Demography, Population, and Ecology Commons, Family, Life Course, and Society Commons, International Public Health Commons, Maternal and Child Health Commons, Obstetrics and Gynecology Commons, and the Women's Health Commons How does access to this work benefit you? Let us know!

\section{Recommended Citation}

Clarke, Kaila, Mohamadou Sall, Babacar Mane, Nafissatou Diop, and Bocar Mamadou Daff. 2014.

"Understanding unintended pregnancy in Senegal: Country profile report," STEP UP Evidence Brief. Dakar: Population Council. 

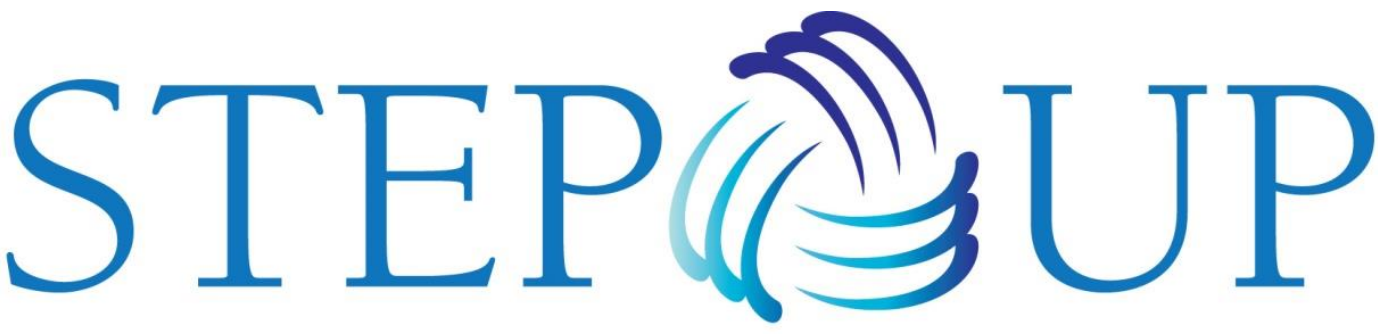

STRENGTHENING EVIDENCE FOR PROGRAMMING ON UNINTENDED PREGNANCY

July 2014

STEP UP generates policy-relevant research to promote an evidencebased approach for improving access to family planning and safe abortion.

We work in Bangladesh, northern India, Ghana, Kenya, and Senegal.

Population Council Coordinating Partner

African Population and Health Research Center

ICDDR,B

London School of Hygiene and Tropical Medicine

Marie Stopes International

Partners in Population and Development

Funded by

\section{UNDERSTANDING UNINTENDED PREGNANCY IN SENEGAL: COUNTRY PROFILE REPORT} summarized below.

\section{INTRODUCTION}

In developing countries, 40 percent of pregnancies are unintended. These unintended pregnancies contribute on one hand to the rapid population growth and the increase in demographic investments, already insupportable. On the other hand, they also lead to a high rate of maternal deaths, especially those due to recourse to unsafe abortions. Most unintended pregnancies result from an unmet need for family planning.

As part of the "Strengthening Evidence for Programming on Unintended Pregnancy (STEP UP)" research program, the Population Council conducted a thorough review of available literature to better understand unintended pregnancy in Senegal. In addition, available surveys data were reviewed and analyzed, and interviews were conducted with key stakeholders to discuss some aspects in more depth.

The Country Profile was discussed during a twoday workshop in Dakar with key governmental actors at central and regional levels, nongovernmental organizations, and civil society players. The report was thereafter finalized by the Institute for Population Development and Reproductive Health (IPDSR). The final report was validated by the Director of Reproductive Health and Child Survival (DSRSE).

The report is composed of 6 chapters

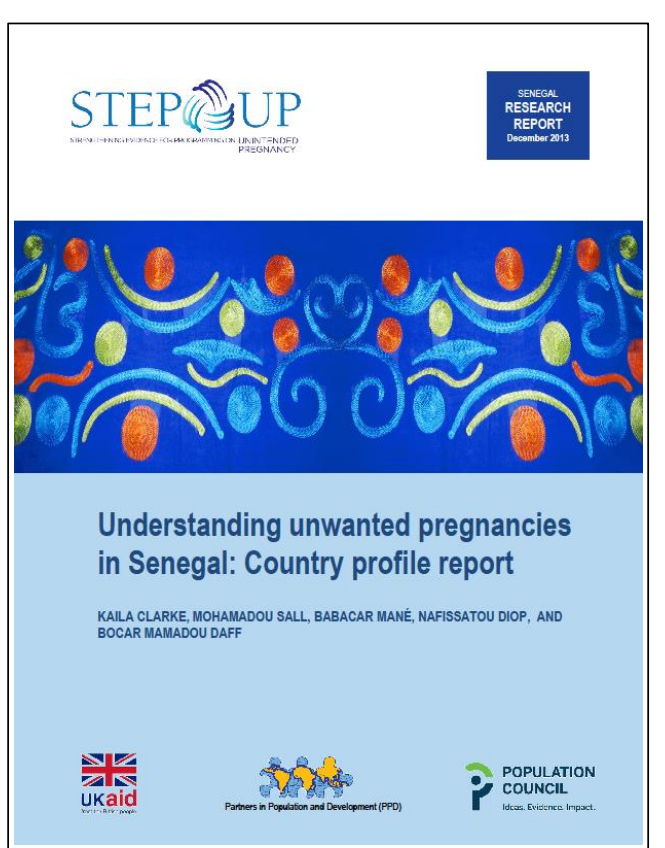

Reference of full report:

Clarke, Kaila, Mohamadou Sall, Babacar Mané, Nafissatou Diop, and Bocar Mamadou Daff. 2013. "Understanding Unintended Pregnancy in Senegal: Country Profile Report," STEP UP Research Report. Dakar: Population Council. 
Sexual and reproductive rights in

Senegal: Legal, political and

\section{sociocultural context}

In recent years, Senegal has adopted several laws, policies and programs that demonstrate a real political will to address these issues. Three major events provided the framework for the integration of issues relating to reproductive health in the national program. These are the Declaration of Population Policy (DPP) adopted in 1988, the International Conference on Population and Development (ICPD) in 1994, and the Millennium Development Goals in 2000. Key reference documents confirmed which, through their principles and strategies, contributed to program implementation.

Thus, policies were adopted to improve reproductive health of populations in general and specific groups such as pregnant women and newborns, adolescents/youth, people living with HIV, and the poor. The adoption of legal texts at the international, regional and national levels allowed for the strengthening of the legal and judicial systems.

Among these measures, there are:

$>$ At the international/regional level : the adoption of the Maputo protocol and the Abuja declaration

$>$ At the national level: the adoption of the RH law and the law on HIVIAIDS.

Measures have also been taken to dissuade early marriage and pregnancies, and to protect the rights of the disabled. However, despite this political will, there are still challenges, especially in terms of increasing access to care, improvement of its quality, and reduction of sociocultural and religious constraints. The legal framework still has weaknesses in regards to the service providers' protection, clients' rights, and abortion rights that remain limited by article 305 of the penal code.

"Any person who attempts to induce an abortion by any means, regardless of the consent of the woman, will be punished by an imprisonment of 1 to 5 years and a fine of 20,000 to 100,000 CFA francs.

\section{Any woman who has had or seeks to have an} abortion or who accepts to use methods for that purpose will be punished by 6 months to 2 years imprisonment and a fine of 20,000 to 100,000 CFA francs."

Article 305 of the Penal Code
Indicators for family planning and reproductive health: analysis of trends and equity

Senegal has a high fertility rate. In 2010 - 2011, the Total Fertility Rate was 5 children per woman, a number close to the ideal number of children wanted by women (5.2) but much less than that desired by men (7.3).

Current use of contraception according to women's age

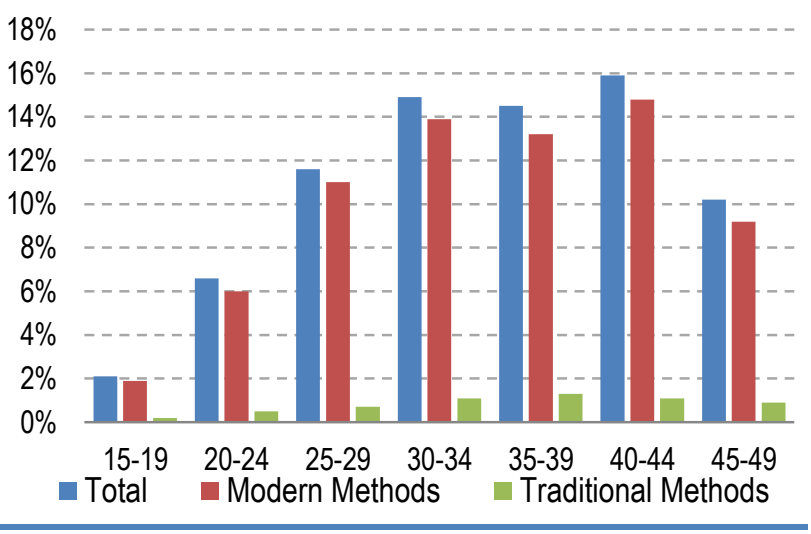

Source : 2010-2011 DHS

Two reasons could be the source of these high rates: early marriage and fertility and a low rate of family planning use. In 2010-2011, only $9.6 \%$ of women used contraception, of which $8.9 \%$ used a modern method (typically injectables and pills for married women and male condoms and injectables for single, sexually active women). This number varies greatly with women's age, marital status, number of living children, place of residence, region, level of education and quintile of wealth.

\section{$24 \%$ of Senegalese women reported experiencing unwanted pregnancies in the five years preceding the 2010-2011 DHS.}

This low use of family planning is at the root of a considerable proportion of unwanted pregnancies: During the $2010-11$ DHS, 20\% of women would have wished to postpone a pregnancy that occurred within the last five years, and $4 \%$ would have liked to have had no pregnancy at all. 
In Senegal, little data exists on the magnitude of abortion due to its illegality which, in turn, leads to recourse to unsafe clandestine practices. However, even if the numbers are approximate, unsafe abortions would be classified as the fifth direct cause of maternal deaths in Senegal. In addition, unsafe abortions would be the cause of about $20 \%$ of maternal morbidity. Lastly, the economic and social consequences of unsafe abortions cannot be neglected.

\section{Access to quality family planning and post-abortion care}

Despite recent investments in infrastructure and human resources in reproductive health services in Senegal, access to information and services for family planning remains low.

In the $2010-11$ DHS, only $7 \%$ of women stated that they had visited a health center over the previous twelve months and talked about family planning. In addition, $60 \%$ of women and $49 \%$ of men had neither heard about nor seen any messages about family planning (on the radio, on television, in newspapers).

In order to obtain contraceptive methods, $85 \%$ of women go to the public sector, $2 \%$ to the private sector and $2 \%$ to other sources such as NGOs.

\section{Supply sources for contraceptive methods by women}

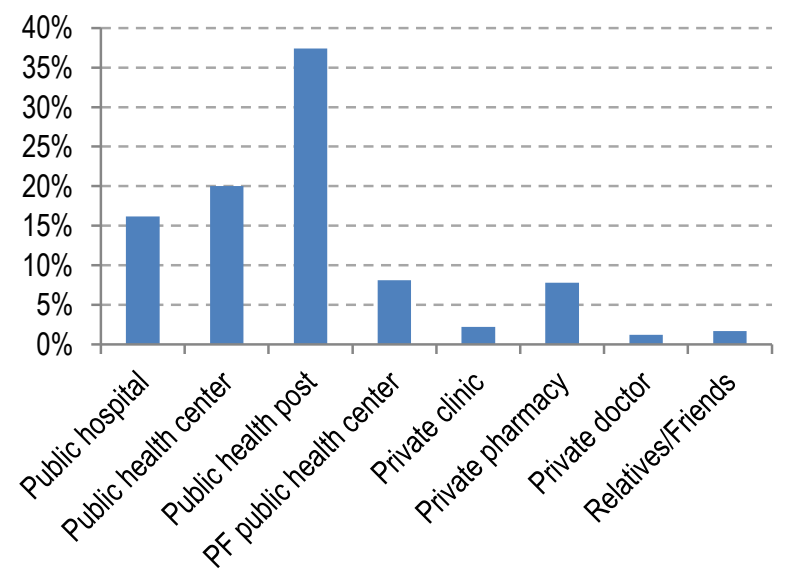

Source : 2010-2011 DHS
Despite the illegality of abortion, Post Abortion Care (PAC) is legal and efforts have been made to improve access. PAC is available in national and regional hospitals, in health centers and numerous public sector health posts. However, the high cost of services could be a barrier to access.

Obstacles to the use of family planning, reproductive health or PAC services are varied. From the supply side, one may point to quality of services, difficulties related to physical and financial access, or stock shortages.

Among demand side obstacles, there is the lack of perception of risk of pregnancy, partner's opposition to family planning, perception that religion is averse to family planning, desire for a large family, poor perception of the quality of services, misinformation and false ideas, or fear of side effects.

\section{Financing and service delivery mechanisms}

Historically, the contribution of the State to the health system has always been weak in relation to the needs of the sector and in reference to recommendations of international commitments, especially recommendations from Abuja that states allocate $15 \%$ of the national budget to public health.

Therefore, Senegal has long been dependent on foreign donors for the provision and management of contraceptive methods; 20 bilateral and multilateral donors contribute to the financing of the health sector, but the part allocated to reproductive health is provided mainly by USAID and UNFPA.

Governmental actors, non-governmental organizations (NGOs), religious organizations and social enterprises also play a role in the provision of products and services and often pool their strengths together.

With the view to strengthening the supply of service mechanisms, alternative approaches such as social marketing, social franchise, community-based distribution or the use of Information Technology and Communication (ITC) are being experimented with. Furthermore, mechanisms to strengthen logistics and product supply as well as advocacy activities contribute to the proper functioning of the system. 


\section{Effects of unintended pregnancies (other than abortions)}

In Senegal, unintended pregnancies are the cause of unplanned births, miscarriages and adoptions.

Furthermore, aside from a rapid population growth and pressure on already limited resources, unwanted pregnancies may lead to an increase in maternal and child mortality.

\section{In Senegal: \\ The maternal mortality rate is 392 deaths per 100,000 live births. One in 43 women dies in childbirth.}

It is estimated that in Senegal, the maternal mortality rate is 392 deaths for 100,000 live births and one woman out of 43 dies in childbirth. The infant mortality rate is high as well with 47 deaths for 1,000 live births.

Unintended pregnancies contribute to these high rates, especially by an increased risk of mortality associated with too closely spaced pregnancies and desperate recourse to infanticide.

Estimates from the Ministry of Health show that if all unmet need for family planning were met, unwanted pregnancies would be practicality eliminated and maternal mortality could be reduced by $20-30 \%$. Virtually eliminating all unwanted pregnancies could lead to a decrease in infant mortality by $12-20 \%$.

\section{If all the unmet need for family planning were met in Senegal, the maternal mortality rate would be reduced by $20-30 \%$ and the infant mortality rate by $12-20 \%$.}

\section{Implications for policy and programs}

Many weaknesses were identified in family planning services, post abortion care, and reproductive health in general. This restricts the ability of the health care system to reduce the number of unwanted pregnancies. In order to improve access to and use of services, efforts must be made to overcome the following obstacles:

Improve the number and the distribution of human resources

Focus on care and the respect of patients in the training of health care personnel in order to address patient hesitancy to seek care due to fear of being judged and poor treatment quality.

> Ensure proper distribution of family planning products and safe abortion supplies according to need through a reinforced coordinating system.

> Improve follow up/evaluation mechanisms to help organize adequate distribution of resources and provide programs the evidence they need to ensure constant evolution of their activities.

Reorganize the National Health Information System and identify bottlenecks and problems programs face in order to resolve them.

Develop a legal framework coherent with the political will to reduce unwanted pregnancies by:

- Relaxing the rules that govern the pharmaceutical sector, rules regulating hormonal contraceptives, and the law penalizing abortion.

- Updating the 2005 Law on Reproductive Health that should be sanctioned by an application decree for effective implementation.

$>$ Take sociocultural factors into account more often and address them more directly, for example, given the important role of religion in Senegal, implementing initiatives that target religious leaders.

$>$ Non-governmental players should pursue their efforts to strengthen programs to produce more immediate effects while ensuring proper coordination amongst themselves. 